\title{
Active ingredients leading in health claims on functional foods
}

Citation for published version (APA):

de Boer, A., Urlings, M. J. E., \& Bast, A. (2016). Active ingredients leading in health claims on functional foods. Journal of Functional Foods, 20, 587-593. https://doi.org/10.1016/j.jf.2015.11.025

Document status and date:

Published: 01/01/2016

DOI:

10.1016/j.jf.2015.11.025

Document Version:

Publisher's PDF, also known as Version of record

Document license:

Taverne

Please check the document version of this publication:

- A submitted manuscript is the version of the article upon submission and before peer-review. There can be important differences between the submitted version and the official published version of record.

People interested in the research are advised to contact the author for the final version of the publication, or visit the DOI to the publisher's website.

- The final author version and the galley proof are versions of the publication after peer review.

- The final published version features the final layout of the paper including the volume, issue and page numbers.

Link to publication

\footnotetext{
General rights rights.

- You may freely distribute the URL identifying the publication in the public portal. please follow below link for the End User Agreement:

www.umlib.nl/taverne-license

Take down policy

If you believe that this document breaches copyright please contact us at:

repository@maastrichtuniversity.nl

providing details and we will investigate your claim.
}

Copyright and moral rights for the publications made accessible in the public portal are retained by the authors and/or other copyright owners and it is a condition of accessing publications that users recognise and abide by the legal requirements associated with these

- Users may download and print one copy of any publication from the public portal for the purpose of private study or research.

- You may not further distribute the material or use it for any profit-making activity or commercial gain

If the publication is distributed under the terms of Article $25 \mathrm{fa}$ of the Dutch Copyright Act, indicated by the "Taverne" license above, 


\title{
Opinions and Perspectives
}

\section{Active ingredients leading in health claims on functional foods}

\author{
Alie de Boer ${ }^{a, *}$, Miriam J. E. Urlings ${ }^{b}$, Aalt Bast ${ }^{a}$ \\ ${ }^{a}$ Department of Pharmacology and Toxicology, Faculty of Health Medicine and Life Sciences, Maastricht \\ University, Maastricht, The Netherlands \\ ${ }^{\mathrm{b}}$ Department of Complex Genetics, Faculty of Health Medicine and Life Sciences, Maastricht University, \\ Maastricht, The Netherlands
}

\section{A R T I C L E I N F O}

Article history:

Received 17 July 2015

Received in revised form 5

November 2015

Accepted 9 November 2015

Available online 8 December 2015

\section{Keywords:}

Bioactives

Functional food

Functional ingredients

Health claims

European food law

EFSA

\begin{abstract}
A B S T R A C T
Defining and characterising the active ingredient is the first criterion in reviewing scientific substantiation of health claims by the European Food Safety Authority under the Nutrition and Health Claim Regulation. This study analyses three health claim dossiers where the active ingredient is directly connected to the food item containing the bioactive. Since this bioactive itself is held responsible for the effect, the association of the food item and the bioactive is not always justifiable. This association is shown to be influenced by both the type of claim and the substantiating evidence. We argue that it would be preferable to more precisely chemically define the active ingredients. Claims could then be based on a bioactive constituent without the necessity to connect the claim to a specific matrix, becoming more transparent and relevant to both the industry and consumers. Characterisation and defining the bioactive should therefore be central in the health claim.
\end{abstract}

(c) 2015 Elsevier Ltd. All rights reserved.

\section{Introduction}

Following various food scares in the 1990s such as the Bovine Spongiform Encephalopathy (BSE) crisis and the dioxin crisis, the EU's approach to food and food safety was radically transformed from an economic perspective to a more consumercentred policy (de Boer, Vos, \& Bast, 2014; Hoad, 2011). One of the 84 proposed actions described in the European Commission (EC)'s White Paper on Food Safety, to achieve 'the highest possible level of health protection', resulted in the development of the Nutrition and Health Claim Regulation (NHCR) in 2006 (European Commission, 2000; European Parliament and Council of the European Union, 2006). Next to improving the functioning of the internal market by harmonisation of laws, the NHCR aims to protect consumers from being misled (European Parliament and Council of the European Union, 2006). It therefore regulates communication about the nutritional content and/or health benefits of a product (European Parliament and Council of the European Union, 2006; Gilsenan, 2011). Scientific substantiation of proposed health claims is assessed by the European Food Safety Authority (EFSA). When

\footnotetext{
* Corresponding author. Department of Pharmacology and Toxicology, Faculty of Health Medicine and Life Sciences, Maastricht University, P.O. Box 616, 6200 MD Maastricht, The Netherlands. Tel.: +31 433882106.

E-mail address: a.deboer@maastrichtuniversity.nl (A. de Boer).

http://dx.doi.org/10.1016/j.jff.2015.11.025

1756-4646/@ 2015 Elsevier Ltd. All rights reserved.
} 
deciding upon authorisation of a health claim, the EC takes into account the scientific opinion of EFSA (de Boer et al., 2014).

EFSA considers three criteria in reviewing the scientific substantiation for a health claim: (i) definition and characterisation of the food or functional ingredient; (ii) definition of the (beneficial physiological) claimed effect; and (iii) establishment of a cause and effect relationship between consumption of the food or functional ingredient and the claimed effect (de Boer et al., 2014; EFSA NDA Panel, 2011a). Subsequent to these criteria, other issues are considered for a claim, .e.g. whether the proposed wording of a claim reflects the provided scientific evidence and whether specific conditions to use a claim on a food product are appropriate (EFSA NDA Panel, 2011a). Following authorisation by the EC, the claim and its accompanying conditions for use can be found in the so-called positive list in the Annex of Regulation 432/2012 (European Commission, 2012b). These specific conditions for use focus on different aspects as the required consumed amount of the food containing the active substance to see the effect, the source of the active ingredient, as well as the matrix in which the active ingredient is presented (European Commission, 2012b).

In this contribution, three health claim dossiers of approved health claims are analysed. We review how the first assessment criterion of defining and characterising the food or functional ingredient for a health claim has been applied by studying these three dossiers. Since from a chemical point of view it would be preferable to focus on a single active component of the functional food or ingredient bearing the claim, we also describe what the result would be of such a novel approach within studying this application of the first assessment criterion.

\section{Olive oil polyphenols}

In 2011, the EC authorised an article 13.1 health claim on the effect of polyphenols in olive oil. The claim states that 'olive oil polyphenols contribute to the protection of blood lipids from oxidative stress'. Although the claim names olive oil polyphenols as active component, the polyphenol content is standardised as hydroxytyrosol and its derivatives (EFSA NDA Panel, 2011c). As a consequence, the claim is exclusively valid for olive oil that contains at least $5 \mathrm{mg}$ of hydroxytyrosol and its derivatives per $20 \mathrm{~g}$ of olive oil (EFSA NDA Panel, 2011c). When these polyphenols are standardised as 'hydroxytyrosol and its derivatives' without defining them, in the claim, consumers will not be made aware about the active component nor why this component is related to the matrix.

Polyphenols, a group of secondary metabolites, are known to protect against oxidative stress and to elicit cardio protecting and anti-inflammatory activity (Hu, He, Jiang, \& Xu, 2014; Li et al., 2014). The main sources of polyphenols are fruits, vegetables, cocoa, tea and olive oil (Hu et al., 2014). Olive oil has been associated with a decreased incidence of cardiovascular disease and lower blood pressure (Storniolo, Roselló-Catafau, Pintó, Mitjavila, \& Moreno, 2014). As such, the health effects of the Mediterranean diet have been attributed to the high consumption of olive oil (Klonizakis, Alkhatib, \& Middleton, 2014; Widmer, Flammer, Lerman, \& Lerman, 2014).

\subsection{Hydroxytyrosol}

The main phenolic compound present in olive oil is hydroxytyrosol (Bast \& Haenen, 2014), together with oleuropein and tyrosol (Hu et al., 2014) and has been considered as a good natural antioxidant (Achmon \& Fishman, 2015). As part of olive oil, hydroxytyrosol is the most abundant and most potent antioxidant, which can be present in several forms (Fernández-Mar, Mateos, García-Parrilla, Puertas, \& Cantos-Villar, 2012; Torres de Pinedo, Peñalver, \& Morales, 2007). During the maturation of olives and storage of olive oil, oleuropein is hydrolysed into hydroxytyrosol, which is therefore mostly present in olive oil and olive mill waste waters (Hu et al., 2014). In addition, hydroxytyrosol can be present both in the free form and as hydroxytyrosol acetate (Fernández-Mar et al., 2012). Hydrolysis of oleuropein into hydroxytyrosol continues after ingestion of the olive oil, increasing the proportion of hydroxytyrosol in olive oil even more inside the body (Rietjens, Bast, \& Haenen, 2007). Hydroxytyrosol is not only abundant in olive oil, but it can be easily obtained from olive leaf and mill waste water, which is a by-product of olive oil production (Bast \& Haenen, 2014; de Bock et al., 2013; Yuan, Wang, Ye, Tao, \& Zhang, 2015). Via these routes, consumption of hydroxytyrosol can be enhanced by using it as a preservative or as active ingredient in functional foods, pharmaceuticals or cosmetics to prevent oxidation (Bast \& Haenen, 2014). The free radical scavenging capacity of hydroxytyrosol can be attributed to its molecular structure, i.e. two phenolic hydroxyl groups. These hydroxyl groups are known for their ability to donate hydrogen atoms to the free radical and thereby terminate the oxidation process (Torres de Pinedo et al., 2007). Currently, hydroxytyrosol and its derivatives as present in olive oil, and related products, is the only phenol recognised by EFSA as a protector of blood lipids from oxidative damage (Achmon \& Fishman, 2015).

\subsection{Chemically produced hydroxytyrosol}

Where hydroxytyrosol in this claim is directly (connected to) olive oil and related products, hydroxytyrosol is found in other natural sources and can even be produced synthetically (Achmon \& Fishman, 2015; Fernández-Mar et al., 2012).

Because of its antioxidant capacity, hydroxytyrosol is an interesting food preservative in other products other than olives. Research into the production of a chemical form of hydroxytyrosol, as a cheap and more convenient alternative to be used as preservative, has led to the development of hydroxytyrosol acetate (Gordon, Paiva-Martins, \& Almeida, 2001; Trujillo et al., 2006). Hydroxytyrosol in its free form and hydroxytyrosol acetate are very much alike and are both present in olive oil and related products (Hu et al., 2014). In the digestive tract, hydroxytyrosol acetate is easily converted into hydroxytyrosol, similar to the form in olive oil, and acetic acid.

\subsection{The claim}

The health effect of olive oil polyphenols as described in the claim involves the protection of low-density lipoprotein (LDL) particles from oxidative damage, which can be attributed to the potency of hydroxytyrosol to scavenge free radicals. Still the active ingredient in the claim is defined as 'olive oil poly- 
phenols', which is later standardised by the content of hydroxytyrosol and its derivatives. The potency of hydroxytyrosol, which can also be obtained from other natural and chemical sources, to scavenge free radicals is not limited to its activity in olive oil. By emphasising in the opinion the importance of hydroxytyrosol and its derivatives, from a chemical perspective it would be more accurate to define these specific components in the claim instead of defining them as 'olive oil polyphenols'.

\section{Cocoa flavanols}

The health claim 'cocoa flavanols help maintain the elasticity of blood vessels, which contributes to normal blood flow' was authorised for use in 2013 by the EC, as an article 13.5 claim on the effects of cocoa flavanol consumption (European Commission, 2013). Flavanols are one of the eight subclasses of flavonoids (Aron \& Kennedy, 2008). Various compounds belong to this group of active substances, varying in their degree of polymerisation from monomeric structures to polymers (de Pascual-Teresa, Moreno, \& García-Viguera, 2010; Donovan et al., 2002).

\subsection{Epicatechin}

In characterising cocoa flavanols, the bioactive components are considered to be the monomeric catechins (primarily epicatechin) and oligomeric flavanols (procyanidins) (EFSA NDA Panel, 2012). In the opinion, only monomers and rarely dimers are considered to be absorbed after oral consumption, attributing the acute effect of cocoa flavanols on blood vessels to those components and not to the unabsorbed procyanidins (EFSA NDA Panel, 2012). The potential health effects of these procyanidins are highly debated, suggesting procyanidins are degraded by the gut microbiota, which results in new bioactive components possibly affecting health (Aron \& Kennedy, 2008; de Pascual-Teresa et al., 2010). The evidence to substantiate this potential long-term health effect is not considered to be sufficient to substantiate a health claim (EFSA NDA Panel, 2012).

Flavanols can be found in cocoa as well as in various other dietary sources such as wine, tea and fruit (de Pascual-Teresa et al., 2010). The intake of monomeric flavanols is mainly attributable to chocolate and green tea (Arts, Hollman, \& Kromhout, 1999; Manach, Scalbert, Morand, Remesy, \& Jimenez, 2004; Song \& Chun, 2008). Of the total amount of flavanols in chocolate, 34-37\% are monomeric flavanols (EFSA NDA Panel, 2012). In grape seed extracts, this amount is approximately $25 \%$ with (-)-epicatechin being almost half of these monomeric flavanols (Weseler et al., 2011).

\subsection{The claim}

In the opinion, the claimed health effect is attributed to monomeric flavanols as epicatechin, leading to specific conditions of use of the claim: the claim can only be used on cocoa products containing at least $34-37 \%$ epicatechin. When the claimed health effect would be solely attributable to these monomeric flavanols, it would be preferable from a chemical perspective to specifically define these flavanols instead of using this generic term. This would give rise to the possibility of other products containing 34-37\% monomeric flavanols (in their total flavanol content) to be allowed to make a similar claim.

\section{4. $\quad \beta$-Glucans}

Four health claims on the effects of $\beta$-glucans naturally present or added to foods are authorised for use in the EU: two article 13.1 claims and two article 14.1(a) claims, as described in Table 1 (European Commission, 2011, 2012a, 2012b). The source of $\beta$-glucan is specified in either the wording of claims or the conditions for use and is either barley or oats.

\begin{tabular}{|c|c|c|}
\hline Claim type & Suggested wording of claim & Conditions \\
\hline Art 13.1 & $\begin{array}{l}\text { Regular consumption of } \beta \text {-glucans contributes to } \\
\text { maintenance of normal blood cholesterol } \\
\text { concentrations. }\end{array}$ & $\begin{array}{l}\text { Food bearing claim must contain } \geq 1 \mathrm{~g} \text { of } \beta \text {-glucans from oats, oat } \\
\text { bran, barley, barley bran, or mixtures of these sources per quantified } \\
\text { portion. } \\
\text { Information must be provided that the beneficial effect is obtained } \\
\text { with a daily intake of } 3 \mathrm{~g} \text { of } \beta \text {-glucans from oats, oat bran, barley, } \\
\text { barley bran, or from mixtures of these beta-glucans. }\end{array}$ \\
\hline Art 13.1 & $\begin{array}{l}\text { Consumption of } \beta \text {-glucans from oats or barley } \\
\text { contributes to the reduction of the glucose rise after } \\
\text { a meal. }\end{array}$ & $\begin{array}{l}\text { Food bearing claim must contain } \geq 4 \mathrm{~g} \text { of } \beta \text {-glucans from oats or barley } \\
\text { for each } 30 \mathrm{~g} \text { of available carbohydrates in a quantified portion. } \\
\text { Information must be provided that the beneficial effect is obtained by } \\
\text { consuming the } \beta \text {-glucans from oats or barley as part of the meal. }\end{array}$ \\
\hline Art 14.1(a) & $\begin{array}{l}\text { Oat } \beta \text {-glucan has been shown to lower/reduce blood } \\
\text { cholesterol. Blood cholesterol lowering may reduce } \\
\text { the risk of (coronary) heart disease. }\end{array}$ & $\begin{array}{l}\text { Foods which provide } \geq 1 \mathrm{~g} \text { oat } \beta \text {-glucans per quantified portion may } \\
\text { use the claim. } \\
\text { Information must be provided that the beneficial effect is obtained by } \\
\text { a daily intake of } 3 \mathrm{~g} \text { of oat } \beta \text {-glucan. }\end{array}$ \\
\hline Art 14.1(a) & $\begin{array}{l}\text { Barley } \beta \text {-glucans have been shown to lower/reduce } \\
\text { blood cholesterol. High cholesterol is a risk factor in } \\
\text { the development of coronary heart disease. }\end{array}$ & $\begin{array}{l}\text { Foods which provide } \geq 1 \mathrm{~g} \text { barley } \beta \text {-glucans per quantified portion may } \\
\text { use the claim. } \\
\text { Information must be provided that the beneficial effect is obtained by } \\
\text { a daily intake of } 3 \mathrm{~g} \text { of barley } \beta \text {-glucan. }\end{array}$ \\
\hline
\end{tabular}




\section{1. $\quad(1 \rightarrow 4)(1 \rightarrow 3) \beta$-D-glucan}

Glucans are non-starch polysaccharides found in various plants, algae and fungi (Synytsya \& Novak, 2014). These soluble dietary fibres consist of glucose polymers, linked by different glycosidic bonds between the monomers (Synytsya \& Novak, 2014). Glucans vary highly in structure, due to differences in e.g. position and distribution of glycosidic bonds or molecular size (Synytsya \& Novak, 2014). The $\beta$-glucans considered in these claims are linear mixed $(1 \rightarrow 4)(1 \rightarrow 3)$ linkages $\beta$-D-glucan, which are mainly found in plants as part of the cell wall of the bran (Skendi, Biliaderis, Lazaridou, \& Izydorczyk, 2003; Synytsya \& Novak, 2014). Mixed $\beta-(1 \rightarrow 4)(1 \rightarrow 3)$ linkages indicate that the polymers are built of blocks of 2 up to 4 glucose units linked by $\beta-(1 \rightarrow 4)$ bonds (approximately $70 \%$ of the mixture), generally separated by $1 \beta$ - $(1 \rightarrow 3)$ linked glucose molecule (approximately $30 \%$ of the mixture) (EFSA NDA Panel, 2009; Skendi et al., 2003).

The health effects of $\beta$-glucans (reducing serum cholesterol levels and post-prandial glucose rise) are ascribed to various physical properties as water solubility, viscosity and gelation properties. These properties are influenced by structural aspects of the molecule such as the molecular weight, the ratio of tri- to tetramers and the ratio of $\beta-(1 \rightarrow 4): \beta-(1 \rightarrow 3)$ linkages (Lazaridou \& Biliaderis, 2007; Synytsya \& Novak, 2014). The dietary fibres form a highly viscous solution in the gut, encapsulating bile acids in the mean bolus. These bile acids become inaccessible for reabsorption, requiring increased bile acids synthesis to replenish the decreased amount of bile acids. Such synthesis leads to decreasing concentrations of circulating LDL cholesterol (EFSA NDA Panel, 2009; Lazaridou \& Biliaderis, 2007). The formation of viscous bulk also delays the rate of nutrient absorption, resulting in lower post-prandial glucose peaks in the blood (EFSA NDA Panel, 2011b).

\subsection{The claim}

Various studies showed differences between the molar ratio of tri- and tetramers of $\beta$-glucan and subsequently their insolubility (Lazaridou, Biliaderis, Micha-Screttas, \& Steele, 2004). Increasing the ratio of tri- to tetramers led to an increased rate of gel structure development (Lazaridou et al., 2004). These structural properties are suggested to lead to specific physical effects, suggesting that this ratio of tri- to tetramers is important for the elicited health effects of $\beta$-glucans. The ratio of $70 \%(1 \rightarrow 4)$ to $30 \%(1 \rightarrow 3)$ links is established in $\beta$-glucans from oat and barley. However, not this apparent important ratio but the specific source of $\beta$-glucans is specified in the claim. Defining this ratio in the claim could increase the possibility to use a claim on $\beta$-glucans from other sources, which do have similar ratios and can subsequently give rise to comparable physical effects.

\section{Discussion}

Under the NHCR, the EC approved various nutrition and health claims following an assessment of their scientific substantiation by EFSA. The first criterion in EFSA's assessment procedure is the definition and characterisation of the active ingredient (EFSA NDA Panel, 2011a). The defined active ingredient is generally associated with the food item carrying the claim, which is justified when this matrix influences the efficacy of this bioactive component (e.g. plant sterols) (Jones \& Jew, 2007). However, as exemplified with the analysed health claims, the functionality of the bioactive component does not have to depend on the source in which it has been characterised. Therefore, from a chemical perspective it would be preferable to build the claim exclusively on the bioactive when the matrix is not influential, rather than on the food item comprising this bioactive.

\subsection{The analysed claims}

The discussed article 13.1 claim on olive oil polyphenols defines hydroxytyrosol and its derivatives as the responsible bioactives. Literature agrees upon the beneficial effect of hydroxytyrosol, because of its prominent amphiphilic antioxidant characteristics (Rietjens et al., 2007). In the claim however the generic term of 'olive oil polyphenols' is used to describe the active components, where in the conditions of use of the claim the specific amount of hydroxytyrosol is used to standardise these olive oil polyphenols.

As described in the opinion on this health claim, most research on hydroxytyrosol has been performed with olive oil containing hydroxytyrosol (EFSA NDA Panel, 2011c). Although this justifies linking hydroxytyrosol to olive oil, the effects of hydroxytyrosol from other sources should not be ignored immediately.

The article 13.5 claim on cocoa flavanols identifies epicatechin as bioactive responsible for the claimed beneficial health effects. When this health effect would also be attributed to specifically epicatechin in the wording of the claim, next to the conditions of use, new claim possibilities would arise for other products containing this bioactive compound. Next to increasing the opportunity to use epicatechin in food products, the transparency upon the real active ingredient would be increased, in this case epicatechin and not the broad category of cocoa flavanols but also in the previous claim of hydroxytyrosol instead of olive oil polyphenols.

In the case of the article 13.1 and 14.1(a) claims on the health effects of the dietary fibre $\beta$-glucan, substantiating evidence was found for the effects of $(1 \rightarrow 4)(1 \rightarrow 3) \beta$-glucan on maintaining cholesterol levels and lowering the glucose rise. The positive health effects are specifically attributed to the ratio of tri- and tetramers, as found in $\beta$-glucan from oat and barley (EFSA NDA Panel, 2009, 2011b). However, the ratio of these $\beta$-glucans in other cereals is not known. When this ratio would have been studied in other sources of $\beta$-glucan by focussing on the chemical composition of the bioactive ingredients, more information would have been available on the potential effects of other cereals. Transparency of the claim and its functional ingredient could be increased by specifying the ratio of $\beta$-glucans in the claim.

\subsection{Type of claim and scientific substantiation}

These examples indicate two elements which influence whether the active ingredient is linked to a specific food component or food matrix in the authorised health claims: (i) the type of claim 


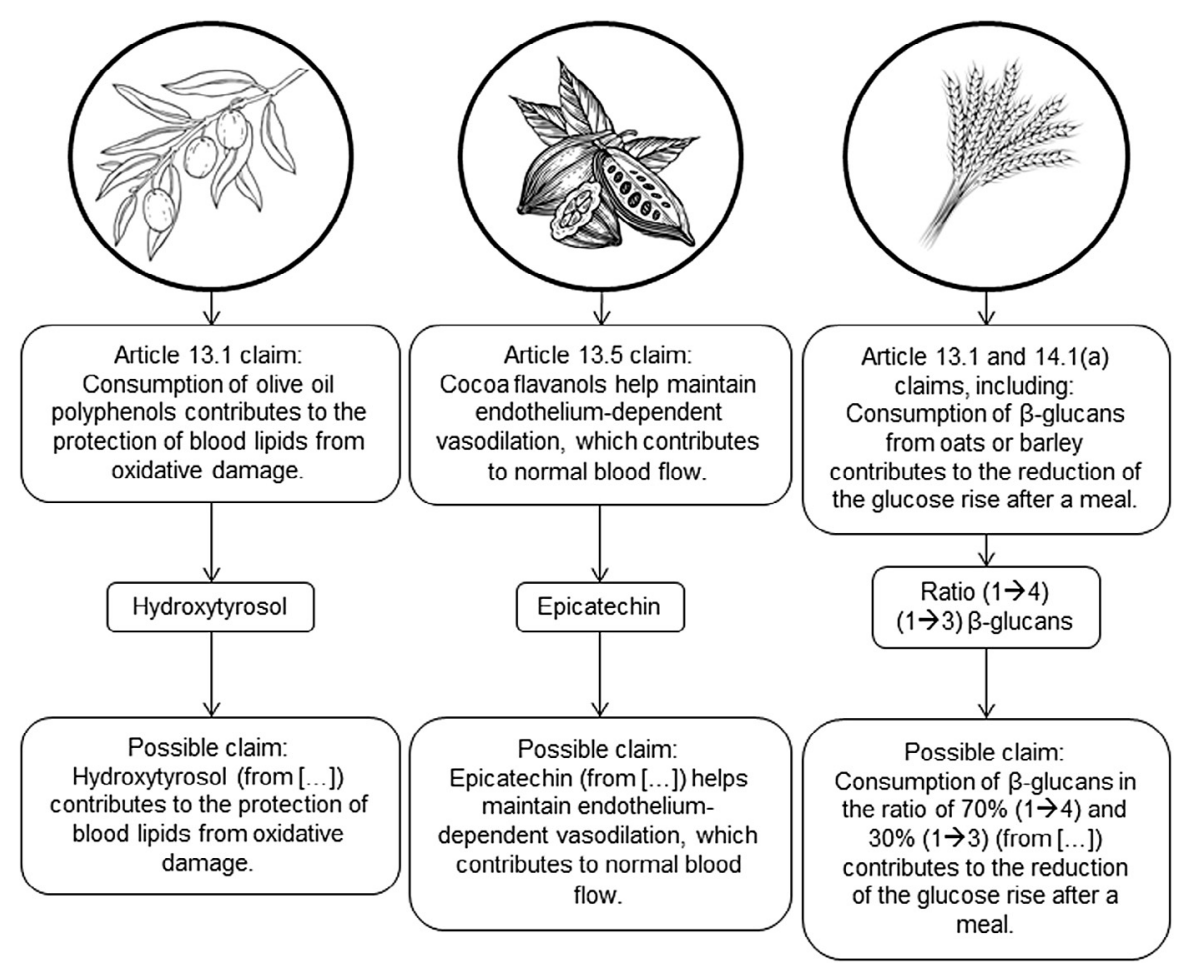

Fig. 1 - Claim possibilities when focussing on bioactives.

considered; and (ii) the substantiating evidence available and delivered in the dossier.

Within the NHCR, three types of health claims are defined: (i) article 13.1 claims: general function claims which imply a health benefit based on generally accepted scientific evidence; (ii) article 13.5 claims: new function claims which imply a health benefit based on newly developed scientific evidence, where the opportunity is given to request protection of proprietary data; and (iii) article 14.1 claims: claims on (a) the reduction of disease risk, describing the positive effect of consumption on a risk factor of a disease or on (b) children's development and health (de Boer et al., 2014; European Parliament and Council of the European Union, 2006).

In the assessment procedure of the article 13.1 claims on both olive oil polyphenols and $\beta$-glucans, all generally accepted scientific evidence is required to be considered. In case of an article 13.5 or 14.1 claim however, the claim is assessed through a specific question. This can lead to the interpretation becoming as narrow as the question itself: when the presented evidence is based only on the active ingredient in a specific matrix, an article 13.5 or 14.1 claim is likely to include this matrix in either the conditions of the claim or in the claim itself (EFSA, 2015). This is seen in the article 13.5 claim on cocoa flavanols, in which epicatechin is the bioactive responsible for the health effect. The studies however all focussed on cocoa flavanols containing 34-37\% monomeric flavanols, and not on epicatechin from other sources.

When the generally accepted scientific evidence to substantiate an article 13.1 claim is only focussed on the bioactive within a specific matrix as hydroxytyrosol in olive oil polyphenols, it is reasonable to focus the claim or its conditions on the active ingredient within this matrix. However, such a general function claim should give rise to the opportunity of using the bioactive from and in other matrices as well. The food industry would be less restricted in using existing as well as new claims, thereby stimulating innovation (de Boer \& Bast, 2015; Moors, 2012).

Next to increasing the opportunities for food industrials to innovate with these well-defined bioactive components, claims also become more transparent by defining the specific bioactive. Thereby understanding of consumers on health enhancing effects of bioactive ingredients might increase. Clarifying communication about specific bioactive ingredients to consumers could gain more understanding upon the effects of nutrition on health. By allowing broader use of more unambiguous claims, consumers will be exposed to more nutrition information and gain more experience with claims, which is suggested to lead to increased relevance of such claims (Dean et al., 2012; van Trijp, 2009). From a chemical perspective it would therefore be preferable to focus research on health effects of food on specific bioactive ingredients. As depicted in Fig. 1, this would subsequently lead to transparent claims on bioactives instead of vague food item claims.

\section{Conclusion}

From a chemical point of view, it would be advisable to standardise an active ingredient to the real bioactive substance such as hydroxytyrosol in the case of olive oil polyphenols, instead of mentioning the broad category of 'olive oil polyphenols'. Authorising the claim for olive oil polyphenols based on its hydroxytyrosol contents narrows the 
possibilities for using hydroxytyrosol in other products while the name of the authorised claim is too generic, possibly leading to consumer confusion. Therefore, standardisation of a health claim via one bioactive ingredient could enhance the opportunities to use such an ingredient in different products. This would be a novel and more practical approach in studying and authorising health claims. When health claims are based on the bioactive constituent without having to be linked to a specific source, claims could be more valuable for both the industry and consumers by stimulating innovation and increasing their relevance. Therefore, characterisation and defining the active ingredient should be central in the health claim.

\section{Conflict of interest}

The authors declare that there are no conflicts of interest.

\section{R EFER E N C E S}

Achmon, Y., \& Fishman, A. (2015). The antioxidant hydroxytyrosol: Biotechnological production challenges and opportunities. Applied Microbiology and Biotechnology, 99(3), 1119-1130. http://doi.org/10.1007/s00253-014-6310-6.

Aron, P. M., \& Kennedy, J. A. (2008). Flavan-3-ols: Nature, occurrence and biological activity. Molecular Nutrition \& Food Research, 52(1), 79-104. http://doi.org/10.1002/mnfr.200700137.

Arts, I. C., Hollman, P. C., \& Kromhout, D. (1999). Chocolate as a source of tea flavonoids. Lancet, 354(9177), 488. http://doi.org/ 10.1016/S0140-6736(99)02267-9.

Bast, A., \& Haenen, G. R. M. M. (2014). Nutritional antioxidants - It is time to categorise. In M. Lamprecht (Ed.), Antioxidants in sport nutrition (pp. 17-38). Boca Raton, FL: CRC Press - Taylor \& Francis Group. http://doi.org/10.1201/b17442-3.

de Bock, M., Thorstensen, E. B., Derraik, J. G. B., Henderson, H., V, Hofman, P. L., \& Cutfield, W. S. (2013). Human absorption and metabolism of oleuropein and hydroxytyrosol ingested as olive (Olea europaea L.) leaf extract. Molecular Nutrition \& Food Research, 57(11), 2079-2085. http://doi.org/10.1002/mnfr .201200795 .

de Boer, A., \& Bast, A. (2015). Stakeholders' perception of the nutrition and health claim regulation. International Journal of Food Sciences and Nutrition, 66(3), 321-328. http://doi.org/ 10.3109/09637486.2014.986071.

de Boer, A., Vos, E., \& Bast, A. (2014). Implementation of the nutrition and health claim regulation - The case of antioxidants. Regulatory Toxicology and Pharmacology, 68(3), 475487. http://doi.org/10.1016/j.yrtph.2014.01.014.

de Pascual-Teresa, S., Moreno, D. A., \& García-Viguera, C. (2010). Flavanols and anthocyanins in cardiovascular health: A review of current evidence. International Journal of Molecular Sciences, 11(4), 1679-1703. http://doi.org/10.3390/ijms11041679.

Dean, M., Lampila, P., Shepherd, R., Arvola, A., Saba, A., Vassallo, M., Claupeine, E., Winkelmann, M., \& Lähteenmäki, L. (2012). Perceived relevance and foods with health-related claims. Food Quality and Preference, 24(1), 129-135.

Donovan, J. L., Lee, A., Manach, C., Rios, L., Morand, C., Scalbert, A., \& Rémésy, C. (2002). Procyanidins are not bioavailable in rats fed a single meal containing a grapeseed extract or the procyanidin dimer B3. British Journal of Nutrition, 87(4), 299-306. http://doi.org/10.1079/BJN2001517.

EFSA. (2015). "New function" health claims under article 13.5. <http://www.efsa.europa.eu/en/topics/topic/article13-5.htm>. Accessed June 2015.
EFSA NDA Panel (2009). Scientific Opinion on the substantiation of health claims related to beta glucans and maintenance of normal blood cholesterol concentrations (ID 754, 755, 757, 801, $1465,2934)$ and maintenance or achievement of a normal body weight (ID 820, 823) pursuant. EFSA Journal, 7(9), Article 1254.

EFSA NDA Panel (2011a). General guidance for stakeholders on the evaluation of Article 13.1, 13.5 and 14 health claims. EFSA Journal, 9(4), 1-24. Article 2135.

EFSA NDA Panel (2011b). Scientific Opinion on the substantiation of health claims related to beta-glucans from oats and barley and maintenance of normal blood LDL-cholesterol concentrations (ID 1236, 1299), increase in satiety leading to a reduction in energy intake (ID 851, 852). EFSA Journal, 9(6). Article 2207.

EFSA NDA Panel (2011c). Scientific Opinion on the substantiation of health claims related to polyphenols in olive and protection of LDL particles from oxidative damage (ID 1333, $1638,1639,1696,2865)$, maintenance of normal blood HDLcholesterol concentrations (ID 1639), Mainte. EFSA Journal, 9(4). Article 2033.

EFSA NDA Panel (2012). Scientific Opinion on the substantiation of a health claim related to cocoa flavanols and maintenance of normal endothelium-dependent vasodilation pursuant to Article 13(5) of Regulation (EC) No 1924/2006. EFSA Journal, 10(7). Article 2809.

European Commission (2000). White paper on food safety. COM (1999) (Vol. 719). Brussels.

European Commission (2011). Commission regulation (EU) No 1160/2011 of 14 November 2011 on the authorisation and refusal of authorisation of certain health claims made on foods and referring to the reduction of disease risk. Official Journal of the European Union L, 296, 26-28.

European Commission (2012a). Commission regulation (EU) No 1048/2012 of 8 November 2012 on the authorisation of a health claim made on foods and referring to the reduction of disease risk. Official Journal of the European Union L2, 310, $38-40$.

European Commission (2012b). Commission Regulation (EU) No 432/2012 of 16 May 2012 establishing a list of permitted health claims made on foods, other than those referring to the reduction of disease risk and to children's development and health. Official Journal of the European Union L, 136(55), $1-40$.

European Commission (2013). Commission Regulation (EU) No 851/2013 of 3 September 2013 authorising certain health claims made on foods, other than those referring to the reduction of disease risk and to children's development and health and amending Regulation (EU) No 432/2012. Official Journal of the European Union L, 235(56), 3-7.

European Parliament and Council of the European Union (2006). Regulation (EC) No 1924/2006 of the European Parliament and of the council of 20 December 2006 on nutrition and health claims made on foods. Official Journal of the European Union L, 404(49), 9-25.

Fernández-Mar, M. I., Mateos, R., García-Parrilla, M. C., Puertas, B., \& Cantos-Villar, E. (2012). Bioactive compounds in wine: Resveratrol, hydroxytyrosol and melatonin: A review. Food Chemistry, 130(4), 797-813. http://doi.org/10.1016/j .foodchem.2011.08.023.

Gilsenan, M. B. (2011). Nutrition \& health claims in the European Union: A regulatory overview. Trends in Food Science \& Technology, 22(10), 536-542.

Gordon, M. H., Paiva-Martins, F., \& Almeida, M. (2001). Antioxidant activity of hydroxytyrosol acetate compared with that of other olive oil polyphenols. Journal of Agricultural and Food Chemistry, 49(5), 2480-2485. http://doi.org/10.1021/ jf000537w. 
Hoad, D. (2011). Scientific method and the regulation of health and nutritional claims by the European Food Safety Authority. Bulletin of Science, Technology and Society, 31(2), 123-133.

Hu, T., He, X.-W., Jiang, J.-G., \& Xu, X.-L. (2014). Hydroxytyrosol and its potential therapeutic effects. Journal of Agricultural and Food Chemistry, 62(7), 1449-1455. http://doi.org/10.1021/ jf405820v.

Jones, P. J., \& Jew, S. (2007). Functional food development: Concept to reality. Trends in Food Science \& Technology, 18(7), 387-390. http://doi.org/10.1016/j.tifs.2007.03.008.

Klonizakis, M., Alkhatib, A., \& Middleton, G. (2014). Long-term effects of an exercise and Mediterranean diet intervention in the vascular function of an older, healthy population. Microvascular Research, 95, 103-107. http://doi.org/10.1016/ j.mvr.2014.07.015.

Lazaridou, A., \& Biliaderis, C. G. (2007). Molecular aspects of cereal $\beta$-glucan functionality: Physical properties, technological applications and physiological effects. Journal of Cereal Science, 46(2), 101-118. http://doi.org/10.1016/j.jcs .2007.05.003.

Lazaridou, A., Biliaderis, C., Micha-Screttas, M., \& Steele, B. (2004). A comparative study on structure-function relations of mixed-linkage $(1 \rightarrow 3)$, $(1 \rightarrow 4)$ linear $\beta$-d-glucans. Food Hydrocolloids, 18(5), 837-855. http://doi.org/10.1016/j.foodhyd .2004.01.002.

Li, A.-N., Li, S., Zhang, Y.-J., Xu, X.-R., Chen, Y.-M., \& Li, H.-B. (2014). Resources and biological activities of natural polyphenols. Nutrients, 6(12), 6020-6047. http://doi.org/ 10.3390/nu6126020.

Manach, C., Scalbert, A., Morand, C., Remesy, C., \& Jimenez, L. (2004). Polyphenols: Food sources and bioavailability. The American Journal of Clinical Nutrition, 79(5), 727-747.

Moors, E. H. M. (2012). Functional foods: Regulation and innovations in the EU. Innovation, 25(4), 424-440.

Rietjens, S. J., Bast, A., \& Haenen, G. R. M. M. (2007). New insights into controversies on the antioxidant potential of the olive oil antioxidant hydroxytyrosol. Journal of Agricultural and Food Chemistry, 55(18), 7609-7614. http://doi.org/10.1021/jf0706934.

Skendi, A., Biliaderis, C. G., Lazaridou, A., \& Izydorczyk, M. S. (2003). Structure and rheological properties of water soluble $\beta$-glucans from oat cultivars of Avena sativa and Avena bysantina. Journal of Cereal Science, 38(1), 15-31. http://doi.org/ 10.1016/S0733-5210(02)00137-6.

Song, W. O., \& Chun, O. K. (2008). Tea is the major source of flavan-3-ol and flavonol in the U.S. diet. The Journal of Nutrition, 138(8), 1543S-1547S.

Storniolo, C. E., Roselló-Catafau, J., Pintó, X., Mitjavila, M. T., \& Moreno, J. J. (2014). Polyphenol fraction of extra virgin olive oil protects against endothelial dysfunction induced by high glucose and free fatty acids through modulation of nitric oxide and endothelin-1. Redox Biology, 2C, 971-977. http://doi.org/10.1016/j.redox.2014.07.001.

Synytsya, A., \& Novak, M. (2014). Structural analysis of glucans. Annals of Translational Medicine, 2(2), 17. http://doi.org/10.3978/ j.issn.2305-5839.2014.02.07.

Torres de Pinedo, A., Peñalver, P., \& Morales, J. C. (2007). Synthesis and evaluation of new phenolic-based antioxidants: Structure-activity relationship. Food Chemistry, 103(1), 55-61. http://doi.org/10.1016/j.foodchem.2006.07.026.

Trujillo, M., Mateos, R., Collantes de Teran, L., Espartero, J. L., Cert, R., Jover, M., Alcudia F., Bautista J., Cer A., \& Parrado, J. (2006). Lipophilic hydroxytyrosyl esters. Antioxidant activity in lipid matrices and biological systems. Journal of Agricultural and Food Chemistry, 54(11), 3779-3785. http://doi.org/10 $.1021 /$ jf060520z.

van Trijp, H. C. M. (2009). Consumer understanding and nutritional communication: Key issues in the context of the new EU legislation. European Journal of Nutrition, 48(1), 41-48. http://doi.org/10.1007/s00394-009-0075-1.

Weseler, A. R., Ruijters, E. J. B., Drittij-Reijnders, M.-J., Reesink, K. D., Haenen, G. R. M. M., \& Bast, A. (2011). Pleiotropic benefit of monomeric and oligomeric flavanols on vascular health - A randomized controlled clinical pilot study. PLoS ONE, 6(12), e28460. http://doi.org/10.1371/journal.pone.0028460.

Widmer, R. J., Flammer, A. J., Lerman, L. O., \& Lerman, A. (2014). The mediterranean diet, its components, and cardiovascular disease. The American Journal of Medicine, 128(3), 229-238. http://doi.org/10.1016/j.amjmed.2014.10.014.

Yuan, J.-J., Wang, C.-Z., Ye, J.-Z., Tao, R., \& Zhang, Y.-S. (2015). Enzymatic hydrolysis of oleuropein from Olea europea (olive) leaf extract and antioxidant activities. Molecules, 20, 29032921. http://doi.org/doi:10.3390/molecules20022903. 